Supplement of Solid Earth, 12, 79-93, 2021

https://doi.org/10.5194/se-12-79-2021-supplement

(C) Author(s) 2021. This work is distributed under

the Creative Commons Attribution 4.0 License.

(c) (1)

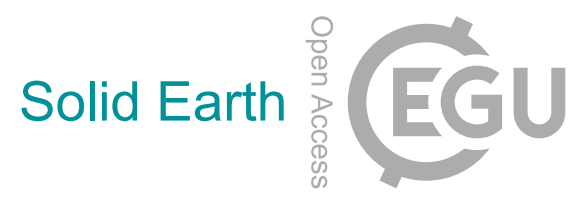

Supplement of

\title{
Effects of basal drag on subduction dynamics from 2D numerical models
}

Lior Suchoy et al.

Correspondence to: Lior Suchoy (1.suchoy17@imperial.ac.uk)

The copyright of individual parts of the supplement might differ from the CC BY 4.0 License. 
This supplement comprises three main sections and references section:

S1. Governing equations and rheology calculations for the numerical models

S2. Illustration of the evolution of all models discussed in the main text

S3. Cenozoic subduction zone parameters

\section{S1. Governing equations and rheology calculations for the numerical models}

We solve flow for incompressible Stokes fluid, under the Boussinesq approximation, assuming mass, momentum and energy conservation equations:

$\partial_{i} u_{i}=0$

$\partial_{i} \sigma_{i j}+\Delta \rho g_{j}=0$

$10 \frac{\partial T}{\partial t}+u_{i} \partial_{i} T-\kappa \partial_{i}^{2} T=0$

where $u$ is the velocity, $\sigma$ is the stress tensor, $g$ is gravity, $T$ is temperature, $\kappa$ is the thermal diffusivity and $\Delta \rho=-\alpha \rho_{s} \Delta T$ is the density difference due to temperature, with $\alpha$ the coefficient of thermal expansion, $\rho_{s}$ the reference (surface) mantle density and $\Delta T$ the difference in temperature from the surface.

Viscosity is therefore the ratio of deviatoric stress to strain rate:

$15 \mu=\frac{\tau_{i j}}{2 \dot{\varepsilon}_{i j}}=\frac{\sigma_{i j}+P \delta_{i j}}{2 \dot{\varepsilon}_{i j}}$

where $\tau$ is the deviatoric stress, $\dot{\varepsilon}$ is the strain rate, $P$ is the dynamic pressure and $\delta_{i j}$ is the delta function. The viscosity is calculated in our models using:

$\mu=\left(\frac{1}{\mu_{\text {diff }}}+\frac{1}{\mu_{\text {disl }}}+\frac{1}{\mu_{y}}+\frac{1}{\mu_{\text {Pie }}}\right)^{-1}$

where $\mu_{\text {diff }}, \mu_{\text {disl }}, \mu_{y}$ and $\mu_{\text {Pie }}$ are the viscosities calculated using diffusion creep, dislocation creep, yielding mechanism

20 and simplified Pierels creep, respectively. The viscosities derived from diffusion, dislocation and Pierels creep are calculated using the generalised equation:

$\mu_{\text {diff } \backslash \text { disl } \backslash P i e}=A^{\frac{-1}{n}} \exp \left(\frac{E+P_{l} V}{n R T_{a d}}\right) \frac{1-n}{\dot{\varepsilon}_{I I}^{n}}$

$P_{l}=\rho g D$

where $A$ is a prefactor, $n$ is the stress exponent, $E$ and $V$ are the activation energy and volume, respectively, $P_{l}$ is the

25 lithostatic pressure, $R$ the gas constant, $\dot{\varepsilon}_{I I}$ is the second invariant of the strain rate tensor and $D$ is the depth. $T_{a d}$ is the 
temperature adjusted with an adiabatic gradient of $0.5^{\circ} \mathrm{K} / \mathrm{km}$ in the upper mantle and $0.3^{\circ} \mathrm{K} / \mathrm{km}$ in the lower mantle (Fowler, 2005). The yielding mechanism is calculated as:

$\mu_{y}=\frac{\tau_{y}}{2 \dot{\varepsilon}_{I I}}=\frac{\min \left(\tau_{s}+f_{c} P_{l}, \tau_{y \max }\right)}{2 \dot{\varepsilon}_{I I}}$

where $\tau_{y}$ is the yield stress, $\tau_{s}$ is the surface yield stress, $f_{c}$ is the friction coefficient and $\tau_{y \text { max }}$ is the maximum yield stress.

30 The viscosity field is capped by both minimum and maximum values. The yielding viscosity is adjusted within the weak decoupling layer by applying a different friction coefficient:

$\mu_{y \text { weak }}=\frac{\min \left(\tau_{s}+f_{c w e a k} P_{l}, \tau_{y \max }\right)}{2 \dot{\varepsilon}_{I I}}$

The initial temperature field in the lithosphere is calculated using the half-space cooling equation from Turcotte and Schubert (2002):

$35 T=T_{S}+\Delta T \cdot \operatorname{erf}\left(\frac{D}{2 \sqrt{\kappa t_{\text {age }}}}\right)$

where $T_{s}$ is the surface temperature and $t_{\text {age }}$ is the age. 


\begin{tabular}{|c|c|c|c|c|c|}
\hline \multirow[t]{2}{*}{ Quantity } & \multirow[t]{2}{*}{ Symbol } & \multirow[t]{2}{*}{ Units } & \multicolumn{3}{|c|}{ Value } \\
\hline & & & $\begin{array}{c}\text { UM } \\
\text { (Reference) }^{\text {(a) }}\end{array}$ & $\begin{array}{c}\text { UM (modified } \\
\text { self-consistent) }^{(b)}\end{array}$ & $\mathbf{L M}^{(\mathbf{a})}$ \\
\hline Gravity & $g$ & $m \cdot s^{-2}$ & \multicolumn{3}{|c|}{9.8} \\
\hline Thermal expansivity coefficient & $\alpha$ & $K^{-1}$ & \multicolumn{3}{|c|}{$3.0 \cdot 10^{-5}$} \\
\hline Thermal diffusivity & $\kappa$ & $m^{2} \cdot s^{-1}$ & \multicolumn{3}{|c|}{$10^{-6}$} \\
\hline Reference (surface) density & $\rho_{s}$ & $\mathrm{~kg} \cdot \mathrm{m}^{-3}$ & \multicolumn{3}{|c|}{3300.0} \\
\hline Cold, surface temperature & $T_{S}$ & \multirow{2}{*}{$K$} & \multicolumn{3}{|c|}{273.0} \\
\hline Hot, mantle temperature & $T_{m}$ & & \multicolumn{3}{|c|}{1573.0} \\
\hline Gas constant & $R$ & $J \cdot K^{-1} \cdot \mathrm{mol}^{-1}$ & \multicolumn{3}{|c|}{8.3145} \\
\hline Maximum viscosity (Strong Lithosphere model) & & \multirow{3}{*}{$\mathrm{Pa} \cdot \mathrm{s}$} & \multicolumn{3}{|c|}{$10^{26}$} \\
\hline $\begin{array}{l}\text { Maximum viscosity (Reference and all other } \\
\text { models) }\end{array}$ & $\mu_{\max }$ & & \multicolumn{3}{|c|}{$10^{25}$} \\
\hline Minimum viscosity & $\mu_{\min }$ & & \multicolumn{3}{|c|}{$10^{18}$} \\
\hline \multicolumn{6}{|l|}{ Diffusion Creep } \\
\hline Activation energy & $E$ & $\mathrm{~J} \cdot \mathrm{mol}^{-1}$ & $300.0 \cdot 10^{3}$ & $335.0 \cdot 10^{3}$ & $200.0 \cdot 10^{3}$ \\
\hline Activation volume & $V$ & $m^{3} \cdot m o l^{-1}$ & $4.0 \cdot 10^{-6}$ & $5.0 \cdot 10^{-6}$ & $1.5 \cdot 10^{-6}$ \\
\hline Pre-factor & $A$ & $P a^{-n} \cdot s^{-1}$ & $3.0 \cdot 10^{-11}$ & $1.5 \cdot 10^{-9}$ & $6.0 \cdot 10^{-17}$ \\
\hline Stress exponent & $n$ & & \multicolumn{3}{|c|}{1.0} \\
\hline \multicolumn{6}{|l|}{ Dislocation Creep (UM) } \\
\hline Activation energy & $E$ & $\mathrm{~J} \cdot \mathrm{mol}^{-1}$ & $540.0 \cdot 10^{3}$ & $472.0 \cdot 10^{3}$ & $300.0 \cdot 10^{3}$ \\
\hline Activation volume & $V$ & $m^{3} \cdot m^{-1}$ & $12.0 \cdot 10^{-6}$ & $11.0 \cdot 10^{-6}$ & $2.0 \cdot 10^{-6}$ \\
\hline Pre-factor & $A$ & $P a^{-n} \cdot s^{-1}$ & $5.0 \cdot 10^{-16}$ & $1.34 \cdot 10^{-17}$ & $10^{-42}$ \\
\hline Stress exponent & $n$ & & 3.5 & 3.472 & 3.5 \\
\hline \multicolumn{6}{|l|}{ Peierls Creep (UM) } \\
\hline Activation energy & $E$ & $\mathrm{~J} \cdot \mathrm{mol}^{-1}$ & $540.0 \cdot 10^{3}$ & $540.0 \cdot 10^{3}$ & $300.0 \cdot 10^{3}$ \\
\hline Activation volume & $V$ & $m^{3} \cdot m^{-1}$ & $10.0 \cdot 10^{-6}$ & $10.0 \cdot 10^{-6}$ & $2.0 \cdot 10^{-6}$ \\
\hline Pre-factor & $A$ & $P a^{-n} \cdot s^{-1}$ & $10^{-150}$ & $10^{-145}$ & $10^{-300}$ \\
\hline Stress exponent & $n$ & & \multicolumn{3}{|c|}{20.0} \\
\hline \multicolumn{6}{|l|}{ Yield Strength Law } \\
\hline Surface yield strength & $\tau_{s}$ & $M P a$ & \multicolumn{3}{|c|}{2.0} \\
\hline Friction coefficient & $f_{c}$ & & \multicolumn{3}{|c|}{0.2} \\
\hline Friction coefficient (decoupling layer) & $f_{c \text { weak }}$ & & 0.02 & 0.07 & 0.02 \\
\hline Maximum yield strength & $\tau_{y \max }$ & $M P a$ & \multicolumn{3}{|c|}{10,000} \\
\hline
\end{tabular}

Table S1-1: Physical and rheological parameters of all models, following the model set-up used by Garel et al., 2014. (a) Activation parameters and stress exponent are consistent with experimental data on olivine (e.g., Karato and Wu, 1993; Hirth and Kohlstedt,

40 1995; Ranalli, 1995; Hirth and Kohlstedt, 2003; Korenaga and Karato, 2008). Lower mantle pre-factor value for dislocation and

Peierls creep are set at a low value to ensure diffusion creep-controlled viscosity in the lower mantle (in accordance with eq. S1.5).

(b) Upper mantle values for the modified self-consistent models were determined using optimisation method described in Maunder et al., 2016. See main text for further details. 
S2. Illustration of the evolution of all models discussed in the main text

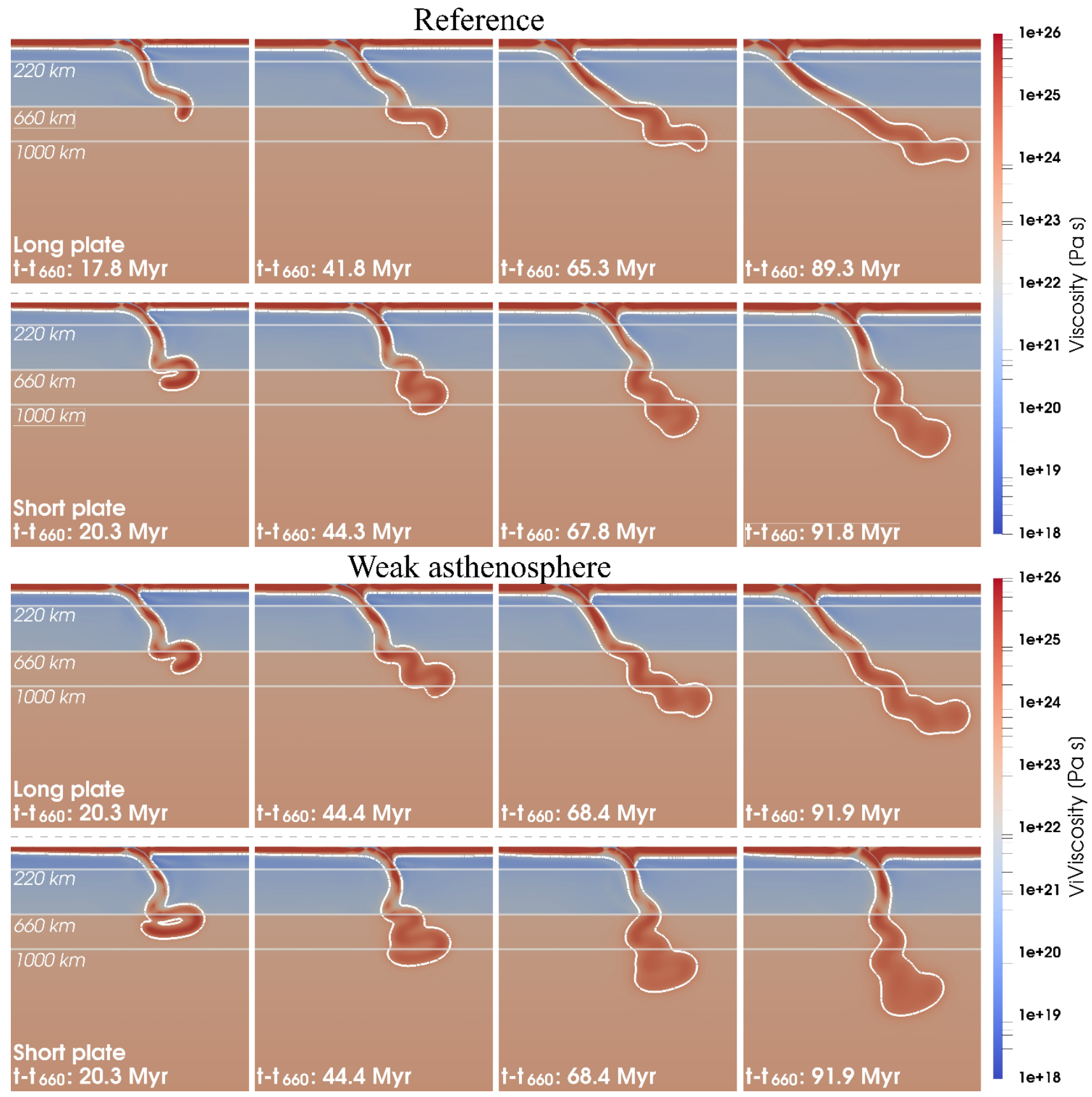

Figure S2-1: Viscosity field evolution at various times, similar to Fig. 3, for the long-plate case (top row of each model) and shortplate case (bottom row of each model) for all models. White contour marks the $1100{ }^{\circ} \mathrm{C}$ isotherm used as the outline of the lithosphere. The vertical and horizontal scales are identical and only part of the full model domain is shown. t-t660 indicates the time since the initial interaction of the slab with the ULMB. Grey lines mark $220 \mathrm{~km}, 660 \mathrm{~km}$ (ULMB) and $1000 \mathrm{~km}$ depths. 


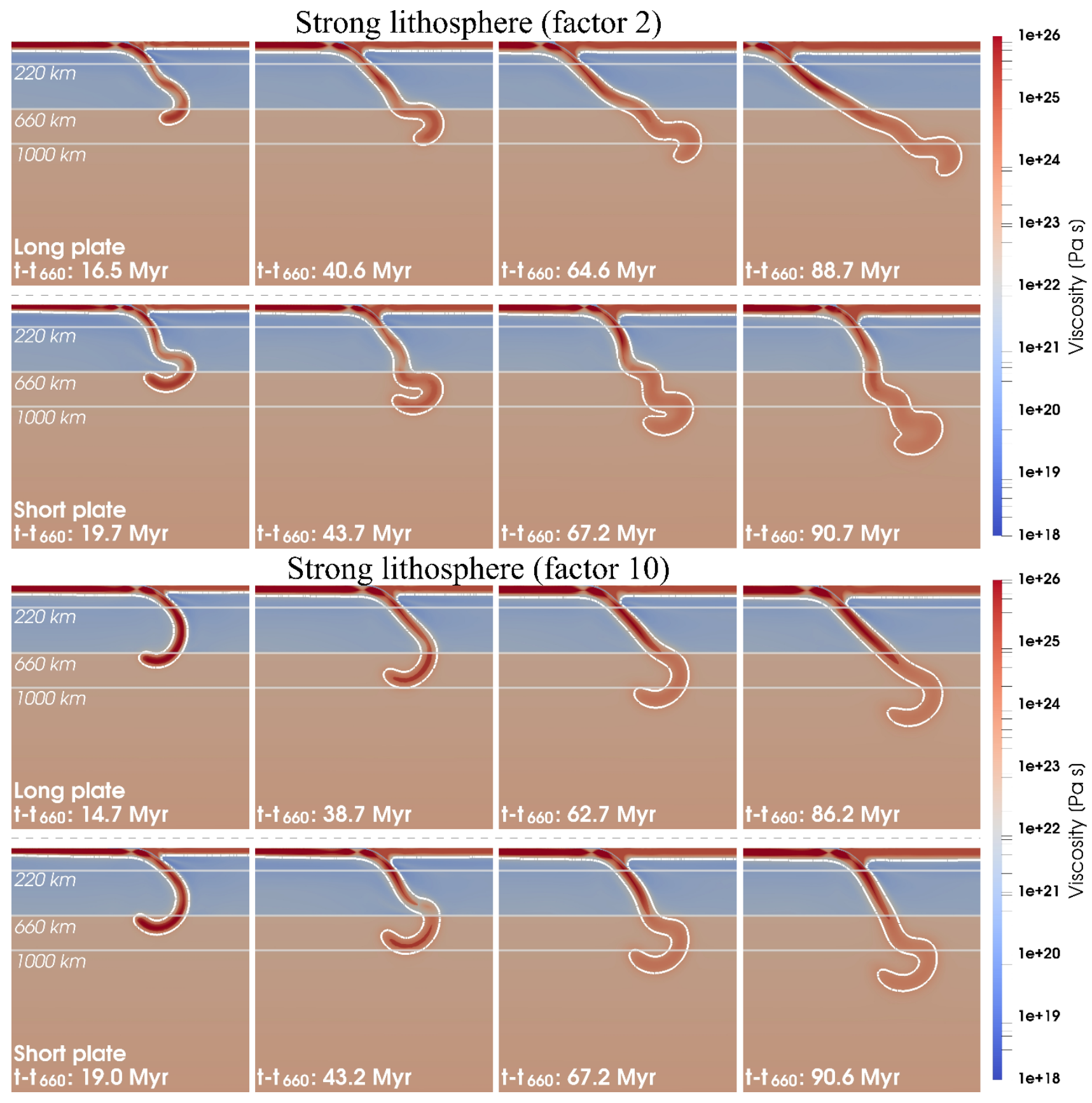

Figure S2-1 (continued) 
Combined weak asthenosphere and strong lithosphere (factor 2)

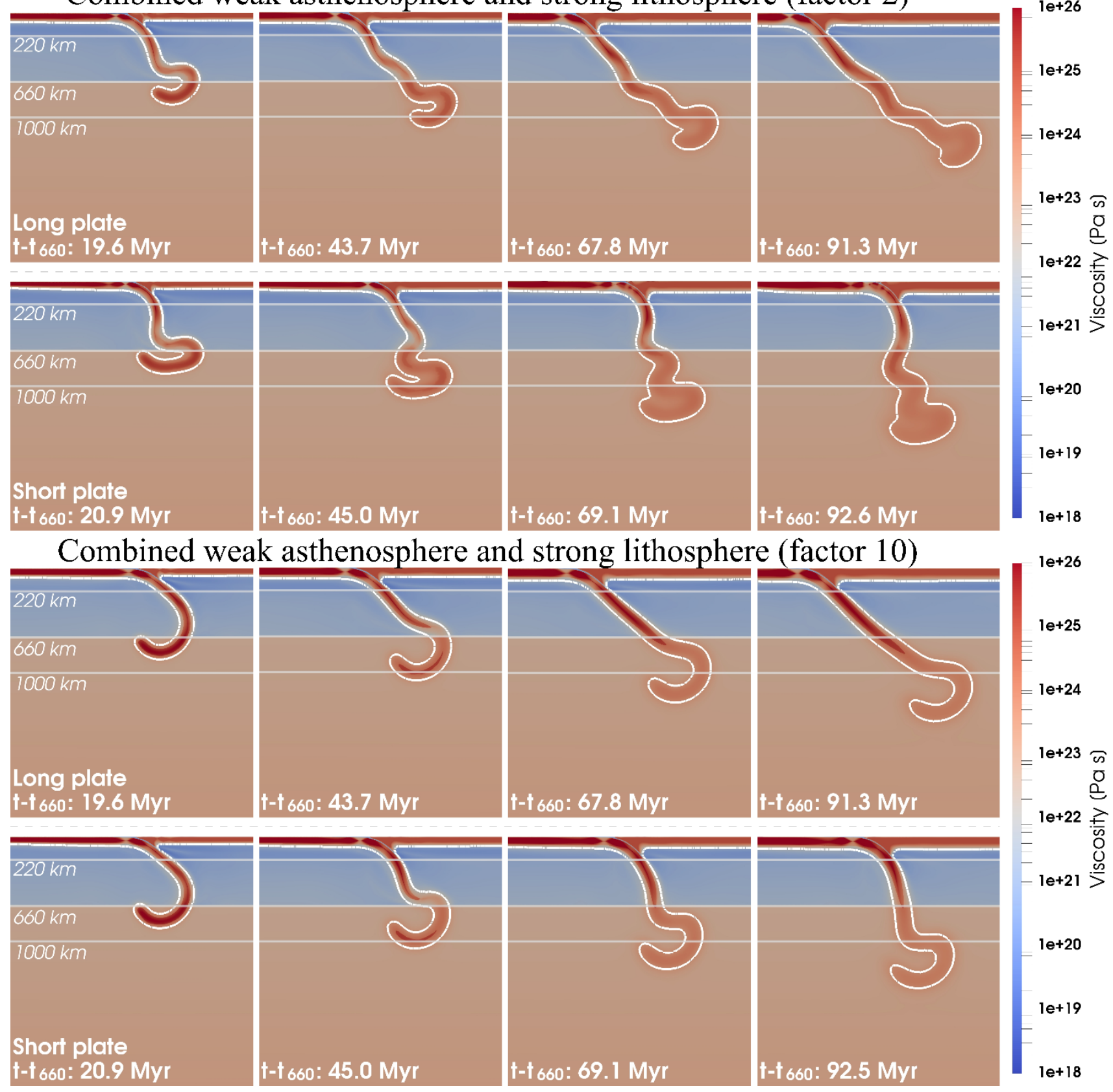

Figure S2-1 (continued) 


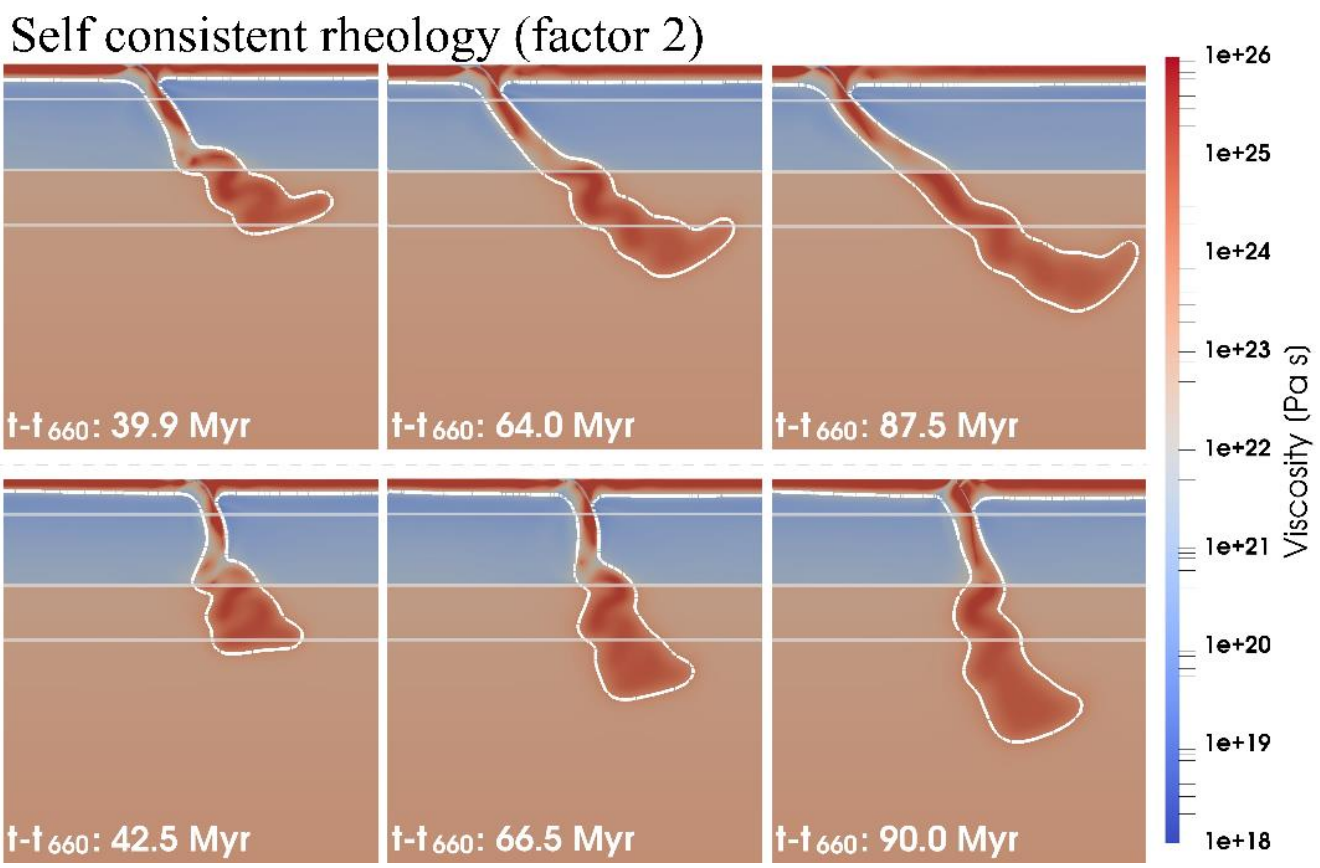

\section{Short plate}

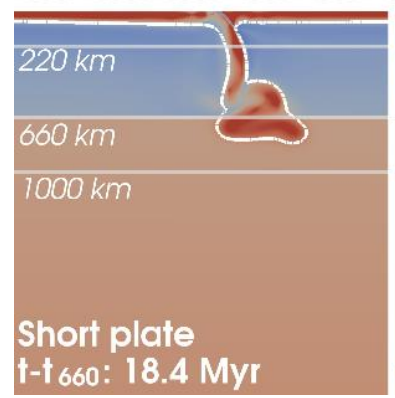

$-t_{660}: 42.5 \mathrm{Myr}$

$\mathrm{t}-\mathrm{f} 660: 66.5 \mathrm{Myr}$

Figure S2-1 (continued)

Figure S2-2: Temporal evolution, similar to Fig. 4,

60 of the long-plate case (full lines) and the short-plate case (dashed lines) for all models. t-t660 indicates the time since the initial

65 interaction of the slab with the ULMB. Panels show (from top left panel, along rows from top to bottom): (1) Velocity of the

70 subducting plate (positive towards the upper plate, red) and the trench (positive away from the upper plate, yellow),

75 measured at $2000 \mathrm{~km}$ distance from the initial subducting plate ridge (left hand boundary). (2) Displacement of the

80 subducting plate (red) and the trench (yellow) relative to the initial condition. (3)

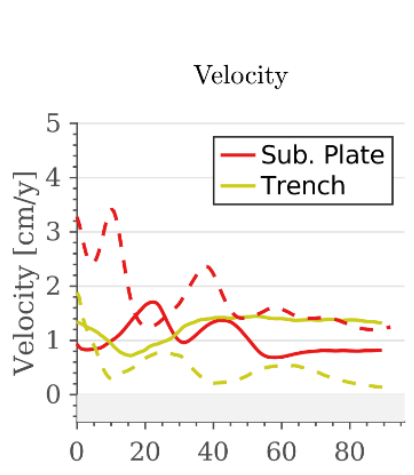

Reference
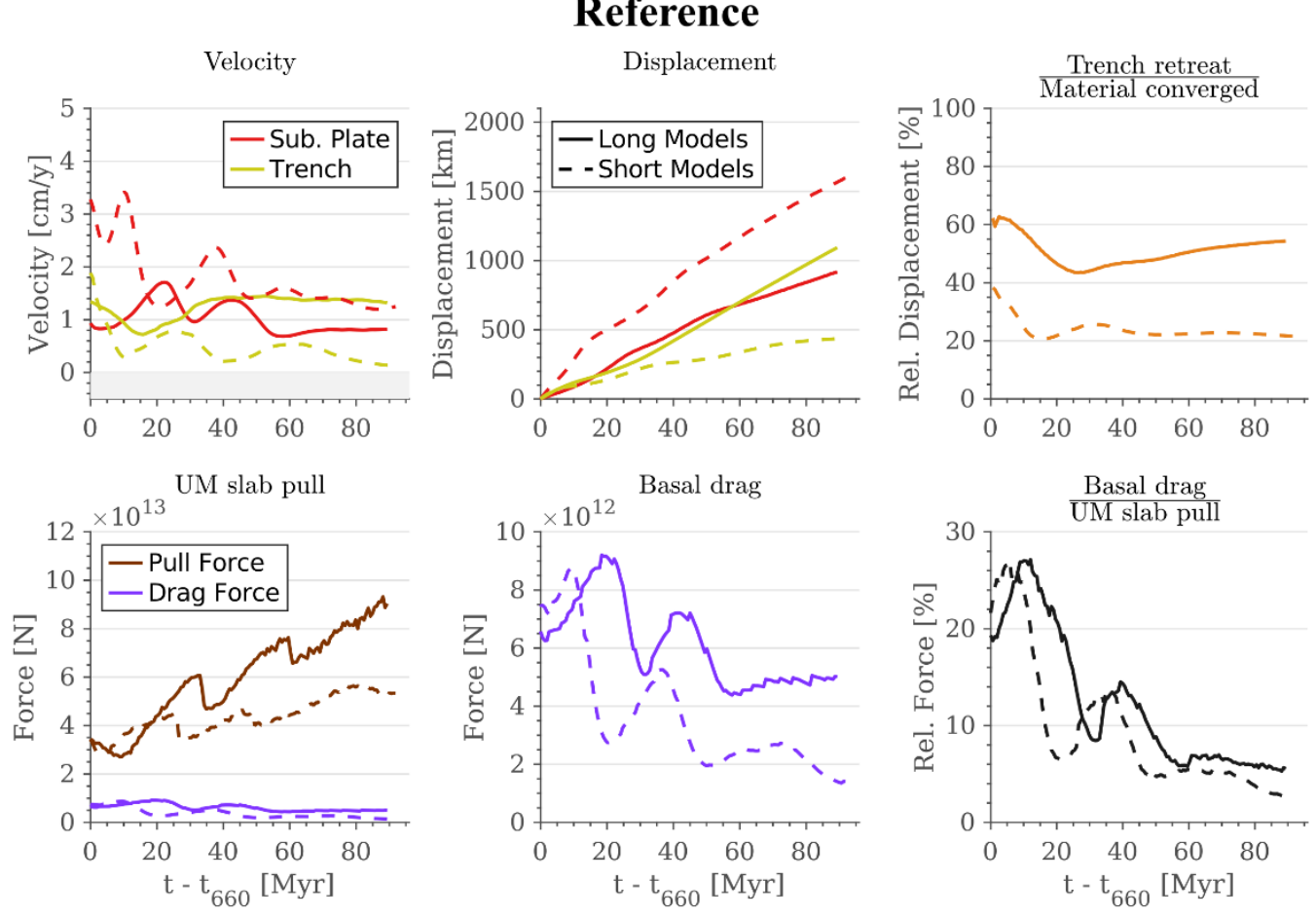

Percent of plate convergence (calculated as the sum of trench retreat and plate displacement) achieved by trench retreat. (4) Upper-mantle slab pull and basal drag below the subducting plate, calculated as described in the main text. (5) Basal drag force from (4). (6) Ratio of basal drag to upper mantle slab pull force. 
Weak asthenosphere
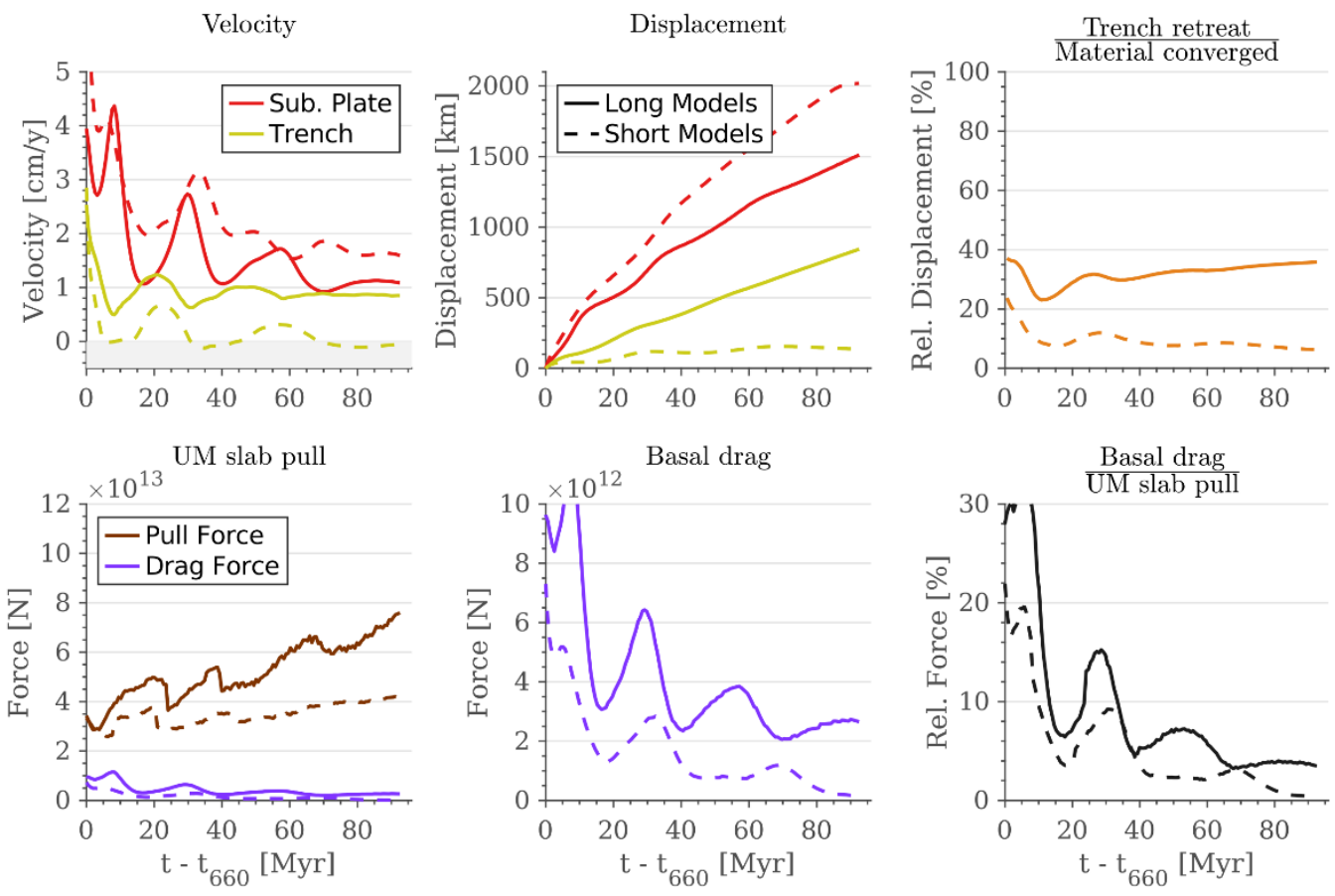

\section{Strong lithosphere (factor 2)}
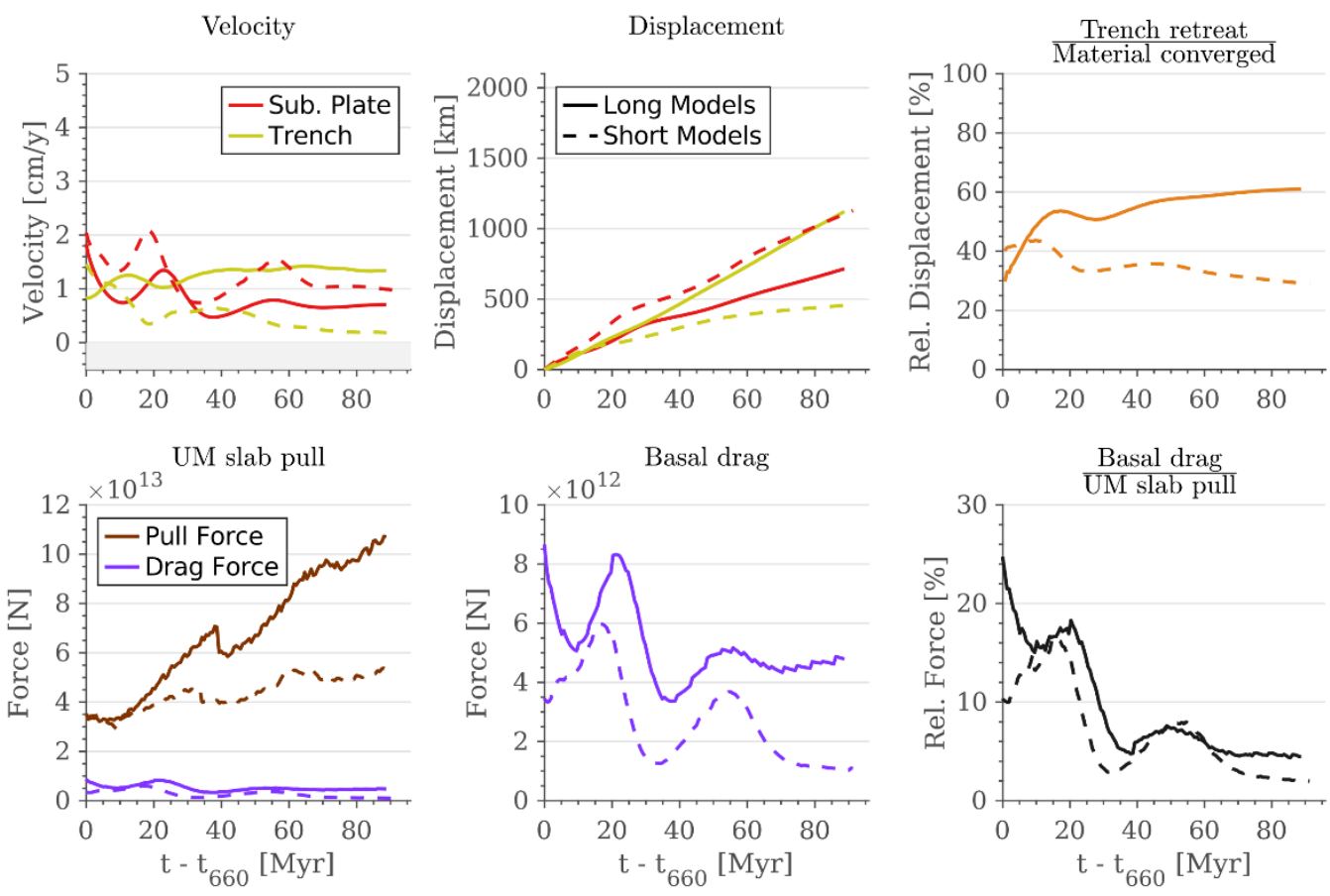

Figure S2-2 (continued) 
Strong lithosphere (factor 10)

Velocity
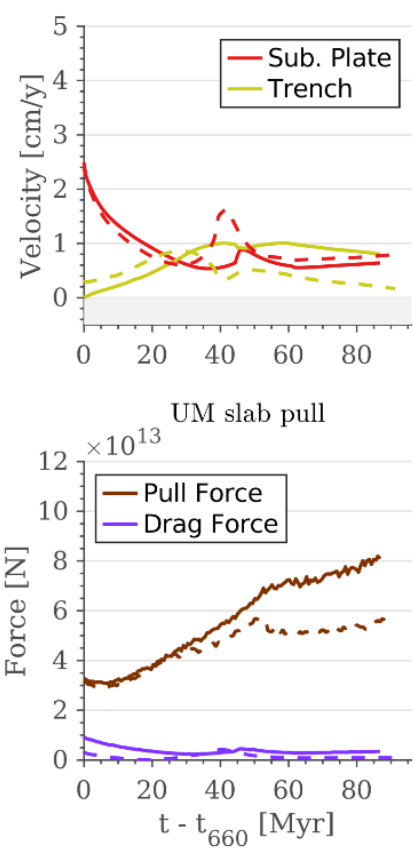

Displacement
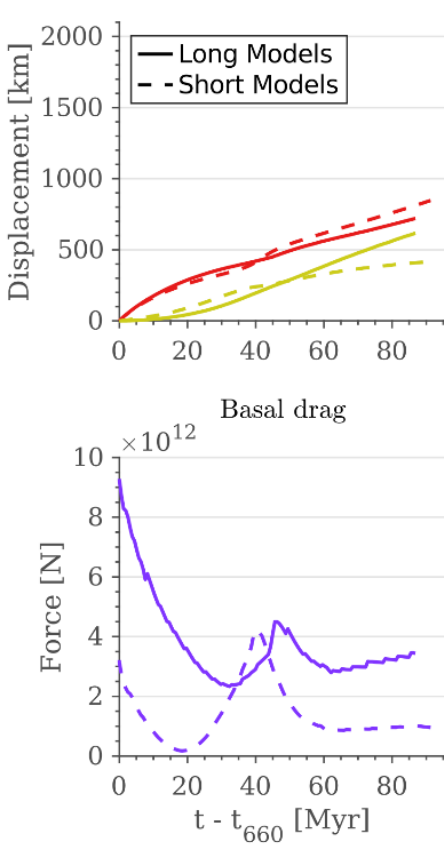

Trench retreat

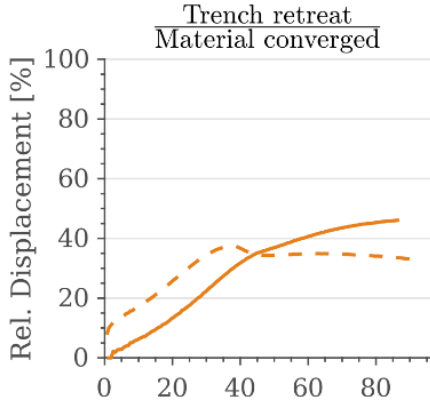

Basal drag

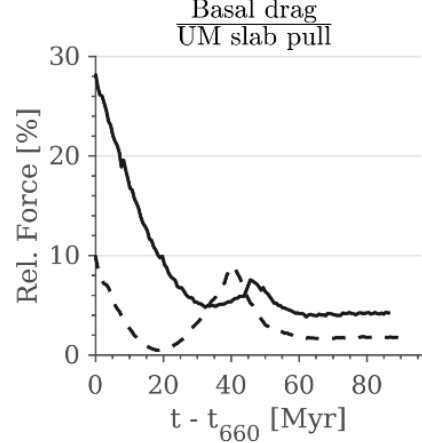

Combined weak asthenosphere and strong lithosphere (factor 2)

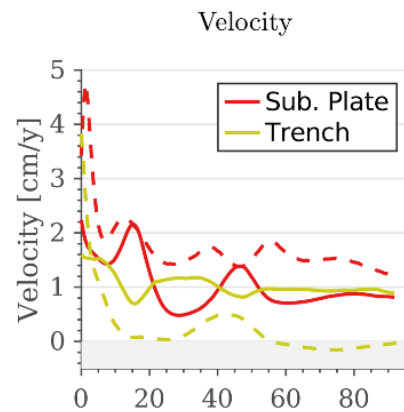

Displacement
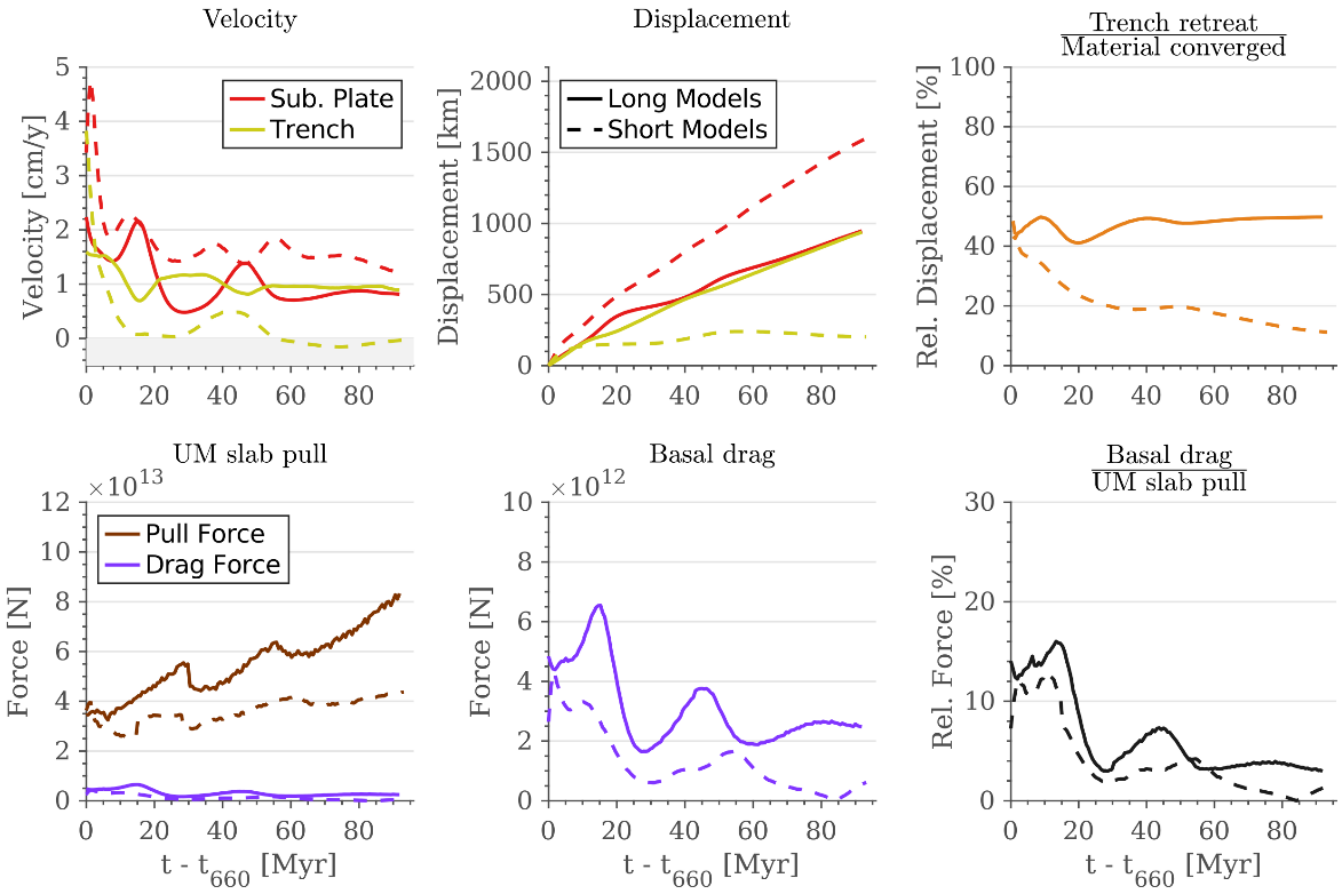

Figure S2-2 (continued) 
Combined weak asthenosphere and strong lithosphere (factor 10)
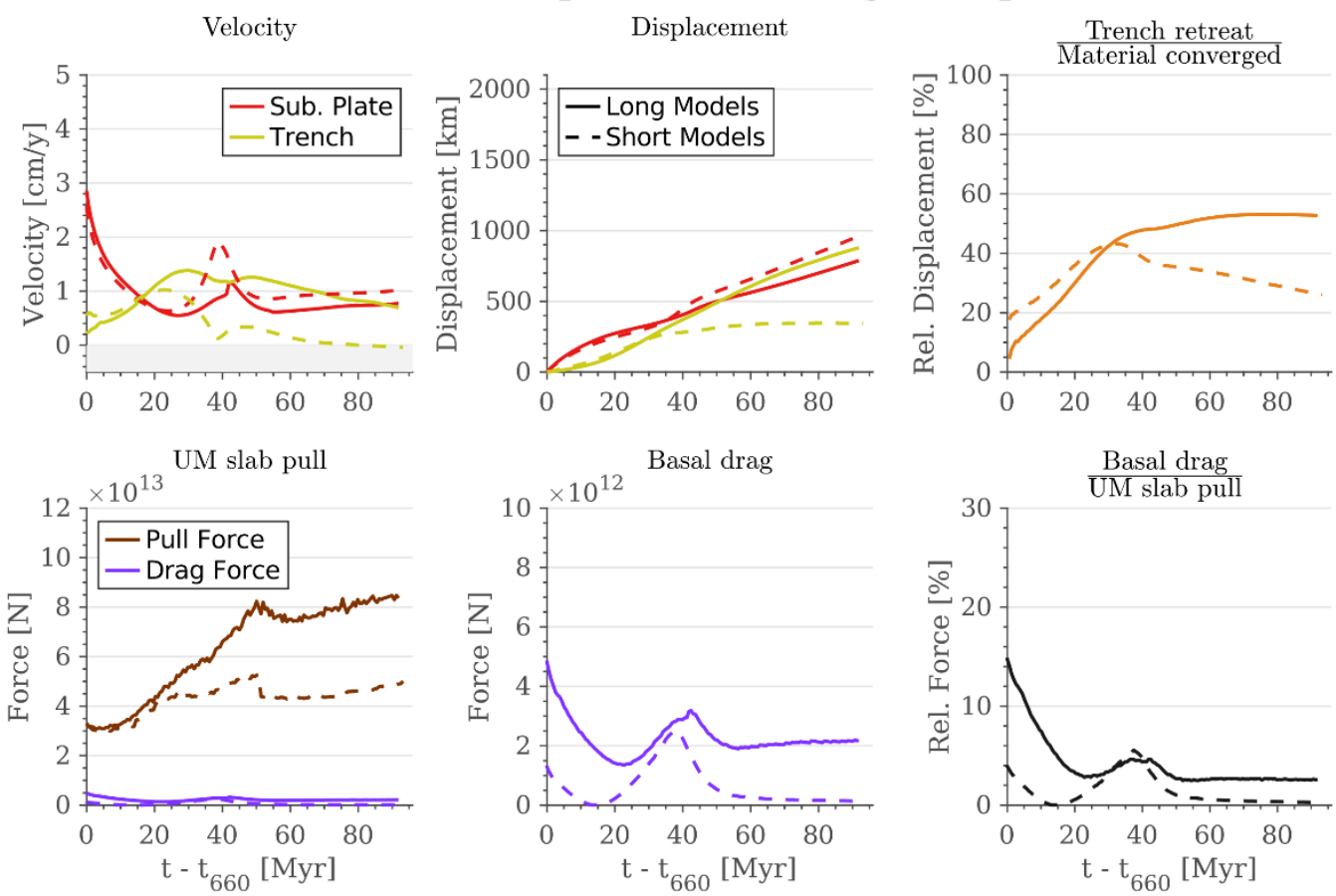

\section{Self consistent rheology}
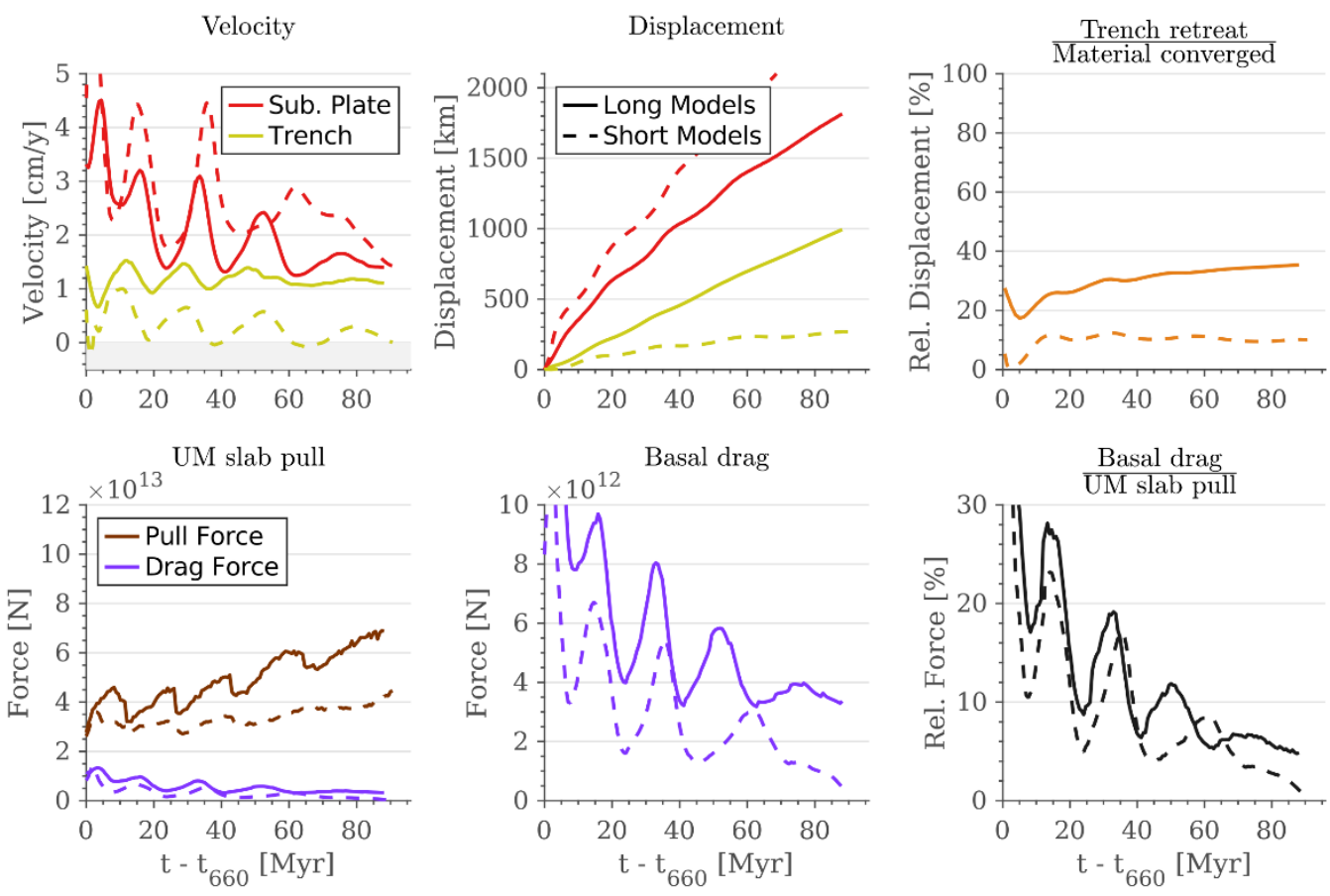

Figure S2-2 (continued) 
(a)

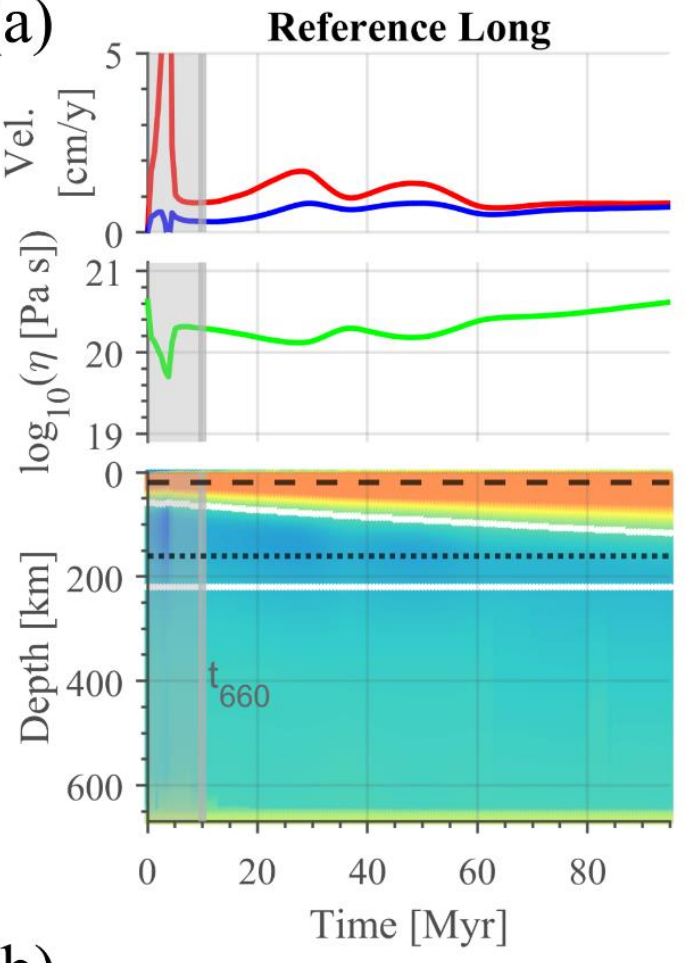

(b)

\begin{tabular}{|l|l|}
\hline $2000 \mathrm{~km}$ \\
\hline $220 \mathrm{~km}$ \\
\hline $660 \mathrm{~km}$ & \\
\hline $1000 \mathrm{~km}$ & \\
\hline
\end{tabular}

Figure S2-3 (a) Temporal evolution of parameters used for the calculation of basal drag (see main text for further details), for the long-plate reference model (left panels) and short-plate reference model (right panels). Top panel shows the velocities of the lithosphere (red line) and asthenosphere (blue line) (measured along the dashed and dotted lines in the bottom panel, respectively). Middle panel shows the magnitude of the viscosity of the asthenosphere (green line, measured along the dotted line in the bottom panel). Bottom panel shows a vertical profile $(0-660 \mathrm{~km}$ depth) of the magnitude of the viscosity field. White lines mark the base of the lithosphere $\left(1100^{\circ} \mathrm{C}\right.$ isotherm) and asthenosphere (constant depth of $\left.220 \mathrm{~km}\right)$. Parameters for the lithosphere were measured at $20 \mathrm{~km}$ depth (black dashed line) and parameters for the asthenosphere at $160 \mathrm{~km}$ depth (black dotted line). Time before the initial interaction of the slab with the ULMB, t660, is not shown in Fig. 4, 6 and 2.2 and shaded in this figure. (b) Location of the vertical profile location along which the quantities in (a) are measured (brown line), marked on an outline of the lithosphere at the initial condition of the long-plate reference model (magenta line) and the short-plate reference model (green line). The vertical and horizontal spatial scales are identical and only part of the full model domain is shown. Grey lines mark $220 \mathrm{~km}, 660 \mathrm{~km}$ (ULMB) and $1000 \mathrm{~km}$ depth. 
We used GPlates (Müller et al., 2018) with the plate reconstruction of Müller et al. (2016) to make an updated compilation of the average velocities, average age at the trench and size of the subducting plates for major subduction zones through the Cenozoic (0-60 Ma). This was done for all trenches previously studied by Sdrolias and Müller (2006) who considered the Andean subduction zone, Central-North Farallon subduction systems, subduction below Alaska and the Aleutians,

110 subduction below Japan-Kuriles-Kamchatka, subduction below Izu-Bonin-Marianas, below Tonga-Kermadec and below the Sunda-Banda arc. To these we added the subduction of the Philippine Sea plate and the final stages of the subduction of the Izanagi and Kula plates. In processing this database, we considered all the Pacific subduction systems (i.e. Alaska-Aleutians, Japan-Kuriles-Kamchatka, Izu-Bonin-Marianas and Tonga-Kermadec) as a single Pacific system.

The relevant trenches were identified by extracting the global subducted segments of all plate polygons in GPlates. All 115 trenches were sampled at $50 \mathrm{~km}$ intervals, and the coordinates were output and then plotted to select those belonging to the major subducting plate systems listed above. For each selected system, age and velocities along the trench were plotted every $10 \mathrm{Myr}$ to check that all data made sense, and to remove edge points where these were clearly anomalous from the rest of the trench (e.g. because of an anomalous age or convergence direction). We evaluated the point velocity of the subducting plate, of the overriding plate as well as convergence velocity and direction to select the segments to analyse. Maps showing the

120 trench segments included in our analysis at each stage can be found in Fig. S3-1, where the sampling points along the trenches are also coloured according to the subducting plate absolute velocity (in the moving hotspot reference frame of O'Neill et al., 2005) and age. These maps illustrate the evolving set of subduction systems through the Cenozoic as well as the variability of age and velocity along each trench. Aside from some edge points, we excluded from our analysis the part of the South American trench at 40 and $50 \mathrm{Myr}$ which was south of the Antarctic ridge and the Cocos subduction system at 20

$125 \mathrm{Ma}$, because according to the plate motion model there is limited convergence along most of the trench at this time. Finally, we considered for our analysis the mean value of the velocities and trench age for each subducting system, and the standard variation of the mean value as the uncertainty. 
There is some variation of both velocity and age along each trench, and each trench has a unique tectonic evolution. Nonetheless, the lack of a trend between velocity and size and the overall correlation between size and age are general features of the Cenozoic set of

135 subduction zones, not dependent on including or excluding one or the other system, or on different definitions of each system, or on consideration of the total subducting plate velocity or only the normal component velocity.Figure S3-1: Evolution of velocities and ages along the trenches considered in the global analysis of Cenozoic subduction systems, in

145 intervals of 10 Myr. 3 maps are shown for each time interval, displaying the trenches used for the analysis (left), absolute subducting plate velocity in hotspot reference frame ( $O^{\prime}$ Neill et al.,

150 2005; middle) and age at the trench (right). Grey lines represent other boundaries of the subducting plates. The background light grey shows present day global coastlines for

155 reference. Data is based on Müller et al. (2016) and processed using GPlates and Cartopy (Met Office, 2015; Müller et al., 2018).
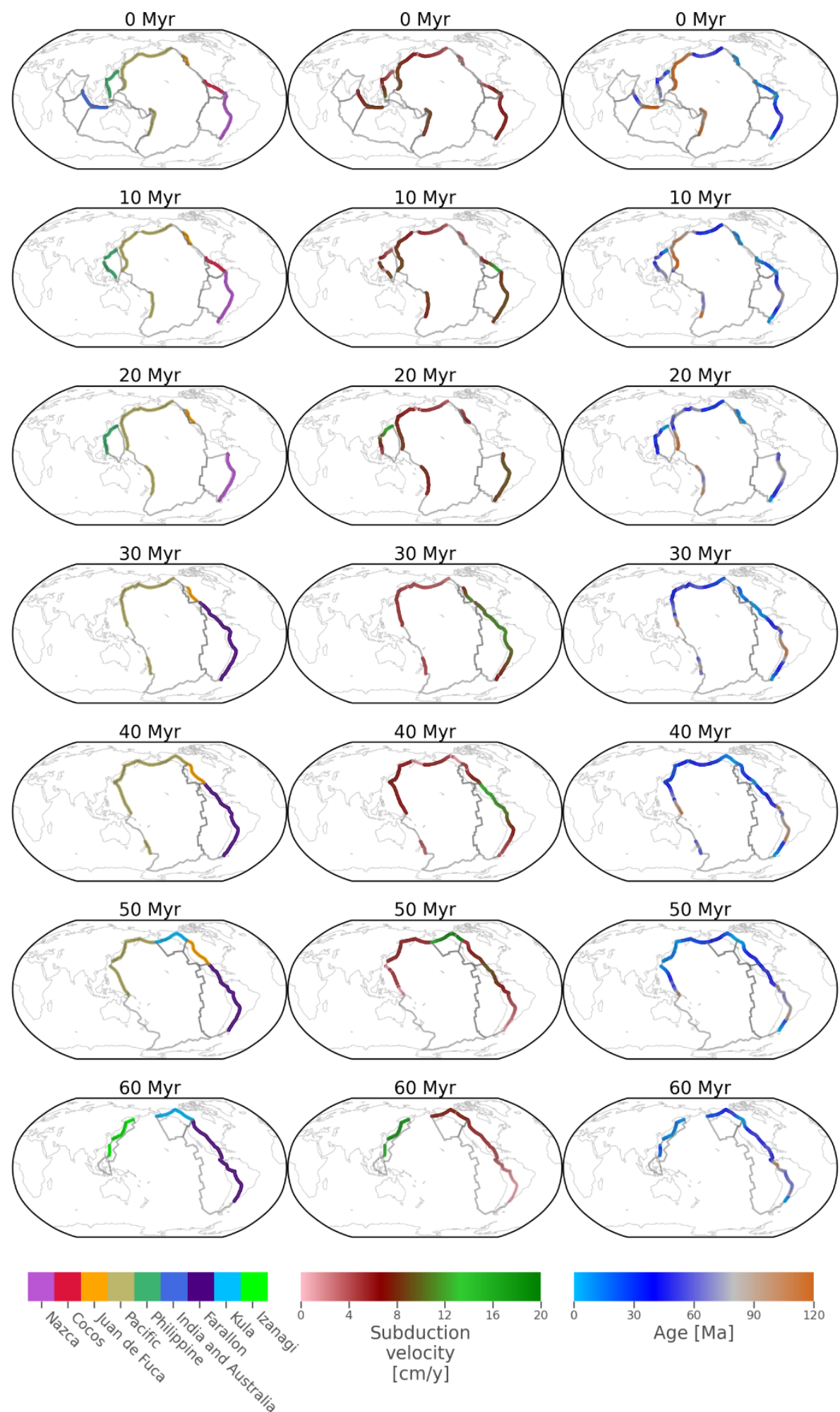

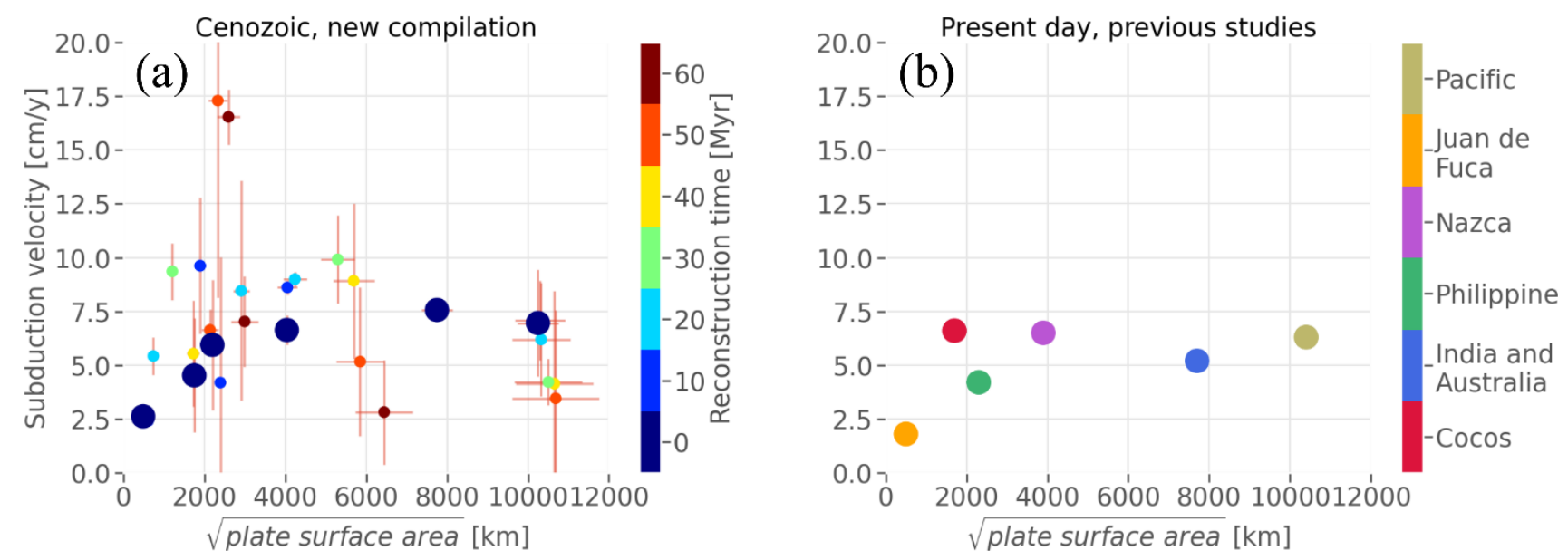

Figure S3-2: Velocity of subducting plates as a function of plate size. Plate size as typical length is calculated as the square root of the surface area of the plate. (a) Cenozoic dataset is based on plate reconstruction from Müller et al. (2016) and analysed using GPlates (Müller et al., 2018). Large markers indicate present day values from this reconstruction. (b) Present day velocities from Schellart et al. (2007) and Sdrolias and Müller (2006), as a function of plate size from Conrad and Hager (1999), same as shown in Fig. 1. All velocities are calculated in lower mantle (plume) reference frame ( $O$ 'Neill et al., 2005).

\section{References}

Fowler, C. (2005), The Solid Earth: An Introduction to Global Geophysics, Cambridge Univ. Press, Cambridge, U. K.

Garel, F., Goes, S., Davies, D. R., Davies, J. H., Kramer, S. C. and Wilson, C. R.: Interaction of subducted slabs with the mantle transition-zone: A regime diagram from 2-D thermo-mechanical models with a mobile trench and an overriding plate, Geochemistry, Geophys. Geosystems, 15, 1739-1765, https://doi.org/10.1002/2014GC005257, 2014.

Hirth, G., and Kohlstedt, D. L.: Experimental constraints on the dynamics of the partially molten upper mantle: Deformation in the diffusion creep regime, J. Geophys. Res., 100, 1981-2001, https://doi.org/10.1029/94JB02128, 1995.

Hirth, G., and Kohlstedt, D. L.: Rheology of the Upper Mantle and the Mantle Wedge: A View from the Experimentalists, Geophys. Monogr. Ser., 138, 83-106, https://doi.org/10.1029/138GM06, 2003.

175 Karato, S., and Wu P.: Rheology of the upper mantle: A synthesis, Science, 260, 771-778, https://doi.org/10.1126/science.260.5109.771, 1993.

Korenaga, J. and Karato, S. I.: A new analysis of experimental data on olivine rheology, J. Geophys. Res.-Sol. Ea., 113, B02403, https://doi.org/10.1029/2007JB005100, 2008.

Maunder, B., van Hunen, J., Magni, V. and Bouilhol, P.: Relamination of mafic subducting crust throughout Earth's history, Earth Planet. Sci. Lett., 449, 206-216, https://doi.org/10.1016/j.epsl.2016.05.042, 2016.

Met Office: Cartopy: a cartographic python library with a Matplotlib interface, Available at: https://scitools.org.uk/cartopy, 2015. 
Müller, R. D., Seton, M., Zahirovic, S., Williams, S. E., Matthews, K. J., Wright, N. M., Shephard, G. E., Maloney, K. T., Barnett-Moore, N., Hosseinpour, M., Bower, D. J. and Cannon, J.: Ocean Basin Evolution and Global-Scale Plate Reorganization Events Since Pangea Breakup, Annu. Rev. Earth Planet. Sci., 44(1), 107-138, https://doi.org/10.1146/annurev-earth-060115-012211, 2016.

Müller, R. D., Cannon, J., Qin, X., Watson, R. J., Gurnis, M., Williams, S., Pfaffelmoser, T., Seton, M., Russell, S. H. J. and Zahirovic, S.: GPlates: Building a Virtual Earth Through Deep Time, Geochemistry, Geophys. Geosystems, 19(7), 22432261, https://doi.org/10.1029/2018GC007584, 2018.

190 O’Neill, C., Müller, D., and Steinberger, B.: On the uncertainties in hot spot reconstructions and the significance of moving hot spot reference frames, Geochem. Geophys. Geosys., 6, Q04003, https://doi.org/10.1029/2004GC000784, 2005.

Ranalli, G.: Rheology of the earth, Chapman and Hall, London, ISBN 0-412-54670-1, 1995

Schellart, W. P., Freeman, J., Stegman, D. R., Moresi, L. and May, D.: Evolution and diversity of subduction zones controlled by slab width, Nature, 446(7133), 308-311, https://doi.org/10.1038/nature05615, 2007.

195 Sdrolias, M. and Müller, R. D.: Controls on back-arc basin formation, Geochem. Geophys. Geosys., 7, Q04016, https://doi.org/10.1029/2005GC001090, 2006.

Turcotte, D. L. and Schubert, G.: Geodynamics, 2nd ed., Cambridge University Press, Cambridge. https://doi.org/10.1017/CBO9780511807442, 2002. 